\title{
Drusen and RPE atrophy automated quantification by optical coherence tomography in an elderly population
}

B Diniz ${ }^{1,2}$, DC Rodger ${ }^{1,3}$, VR Chavali ${ }^{4}$, T MacKay ${ }^{4}$, SY Lee ${ }^{1,3}$, D Stambolian ${ }^{4}$ and SVR Sadda ${ }^{1,3}$

This article has been corrected since Advance Online Publication and a corrigendum is also printed in this issue.

${ }^{1}$ Doheny Eye Institute, Los Angeles, CA, USA

\section{${ }^{2}$ Department of} Ophthalmology, Universidade Federal de São Paulo, São Paulo, Brazil

\section{${ }^{3}$ Department of Ophthalmology, Keck School of Medicine of the University of Southern California, Los Angeles, CA, USA}

\section{${ }^{4}$ Department of}

Ophthalmology, University of Pennsylvania, Philadelphia, PA, USA

Correspondence: B Diniz, Vistta Ophthalmology, Al. Ricardo Paranhos n799, Goiania-GO 74175020, Brazil

Tel: +55 62 96842002;

Fax: +55 6232784004 .

E-mail: drbrunodiniz@ gmail.com

Received: 14 January 2014 Accepted in revised form: 23 September 2014 Published online: 7 November 2014

\begin{abstract}
Purpose Correlate OCT-derived measures of drusen and retinal pigment epithelium (RPE) atrophy areas (RAs) with demographic features in an elderly population.

Patients and methods Subjects aged 50 years and older underwent Cirrus OCT scanning. Drusen area and volume were obtained from the macula within a central circle (CC) of $3 \mathrm{~mm}$ and a surrounding perifoveal ring (PR) of 3-5 mm, using the RPE analysis software (6.0). RA measurements were generated for the $6 \times 6 \mathrm{~mm}^{2}$ retinal area. Gender, age, smoking status, and systolic blood pressure (SBP) were considered.
\end{abstract}

Results A total of 434 eyes were included. RA was larger in women $(0.63 \pm 0.16$ vs $\left.0.26 \pm 0.08 \mathrm{~mm}^{2}, P=0.05\right)$ and with increasing age. The PR drusen area increased with increasing age $(P<0.001)$, whereas the $\mathrm{CC}$ drusen area remained stable after the age of 70 years $\left(0.25 \pm 0.06 \mathrm{~mm}^{2}\right.$ for ages $70-79$ years and $0.25 \pm 0.07 \mathrm{~mm}^{2}$ for ages $>80$ years). Drusen volume in the CC was smaller after the age of 80 years $\left(0.009 \pm 0.003 \mathrm{~mm}^{3}\right)$ compared with the 70- to 79-year-old group $\left(0.02 \pm 0.008 \mathrm{~mm}^{3}\right)$. Drusen measurements were similar between smokers and nonsmokers, but the PR drusen area $\left(0.29 \mathrm{~mm}^{2}, P=0.05\right)$ and volume $\left(0.40 \mathrm{~mm}^{3}\right.$, $P=0.005)$ were correlated with years smoked.

RA $\left(0.24 \mathrm{~mm}^{2}, P=0.10\right)$, PR drusen area $\left(0.29 \mathrm{~mm}^{2}, P=0.05\right)$, and volume $\left(0.40 \mathrm{~mm}^{3}\right.$, $P=0.005)$ were found to be directly associated with SBP. There was a high correlation between the eyes of the same subject. Conclusion OCT-based automated algorithms can be used to analyze and describe drusen and geographic atrophy burden in such population-based studies of elderly patients.
Eye (2015) 29, 272-279; doi:10.1038/eye.2014.260; published online 7 November 2014

Introduction

Age-related macular degeneration (AMD) is the leading cause of irreversible, severe visual loss in developed countries among people of age 50 years and older. ${ }^{1}$ Several studies have identified a multitude of potential risk factors associated with AMD, but the results have not always been conclusive. ${ }^{2}$ Aside from age and cigarette smoking, previous findings of associations between AMD and other risk factors, such as hypertension, alcohol consumption, systolic blood pressure (SBP), sunlight exposure, and cardiovascular disease, have been inconsistent. ${ }^{3}$

Drusen-in particular the large drusen associated with pigment epithelium abnormalities-are a known risk factor for progression to advanced AMD. Drusens are extracellular deposits that accumulate between the retinal pigment epithelium (RPE) and the inner collagenous layer of Bruch's membrane. ${ }^{4}$ Geographic atrophy (GA) occurs in the late stage of non-neovascular AMD and is the second most common cause of severe visual loss due to AMD, the most common being choroidal neovascularization. ${ }^{5}$ GA is characterized by the development and gradual enlargement of atrophic patches that involve the RPE, the overlying neurosensory retina, and the underlying choriocapillaris. ${ }^{6}$

Bilateral involvement of drusen and late-stage AMD have long been recognized, ${ }^{7-9}$ and concordance or symmetry between eyes has been demonstrated for the individual phenotypes. Those studies were based on 
clinical examination or postmortem hitopathological analysis. ${ }^{10}$ Until recently, color fundus photography was the only imaging modality used to evaluate the severity and progression of AMD in major epidemiologic eye disease studies. ${ }^{11}$ However, this imaging technique has limitations with regard to the measurement of the geometric area of RPE atrophy and to the precise quantification of drusen boundaries. Measurement of these types of data is confounded on color fundus photography by interpatient variability of fundus pigmentation and media opacities ${ }^{12}$ and by the exposure settings used.

Optical coherence tomography (OCT) provides the opportunity to assess the effect of drusen and RPE atrophy area (RA) on the geometry of the RPE in vivo. ${ }^{13}$ Segmentation algorithms have been developed to extract quantitative information from the new spectral-domain (SD)-OCT data. Quantification of drusen and RA has been demonstrated with both manual and automated strategies, ${ }^{14}$ and recently automated quantification techniques have become available in commercial SD-OCT (Carl Zeiss Meditec Inc, Dublin, CA, USA) software. Validation of the accuracy and reproducibility ${ }^{13,15,16}$ of these fully automated algorithms has created an opportunity to study AMD lesions in population studies. ${ }^{17}$ To our knowledge, the epidemiologic features of AMD have not previously been associated with automated OCT quantification data. Herein, we describe OCT-derived measures of drusen and RA in an elderly population and correlate these OCT findings with other demographic features.

\section{Methods}

\section{Subjects}

An ongoing study to identify multiple eye diseases in the Old Order Amish community living in Lancaster and Franklin counties in Pennsylvania has identified a large number of Amish individuals with early-late-onset AMD. Details of the epidemiology of AMD in this population are being isolated in an attempt to elucidate genetic factors that may confer susceptibility and predispose some Amish individuals and their families to developing AMD. The current study, approved by the Institutional Review Board of the University of Pennsylvania, was instituted as an investigation to assess the value of the OCT images and quantify changes related to AMD in the macula.

Study participants, all aged 50 years and older, were asked to complete a brief questionnaire about personal exposures. Present or past cigarette smoking history and number of years smoked were self-reported. A qualified examiner obtained SBP on the day of the ophthalmic evaluation. All study participants who agreed to enroll and provide informed consent had digital stereo images of the macula, optical disc, and macular OCT scans.

\section{Optical coherence tomography acquisition}

A Cirrus HD-OCT instrument (Carl Zeiss Meditec Inc) was used for this study. Each eye was imaged in a single session using a volume scan protocol $\left(200 \times 200 \mathrm{~mm}^{3}\right)$ whose repeatability for drusen quantification has been well established and described in the previous publication. ${ }^{13}$ Each scan covered a retinal area of $6 \times 6 \mathrm{~mm}^{2}$, centered on the fovea, and was obtained after dilation. The scans were assessed after acquisition and repeated if necessary to achieve optimal image quality (signal strength $>7$ ).

\section{Quantification of drusen and $R A$}

The raw OCT datasets were exported to a computer for analysis with an algorithm developed by Zeiss used to segment the RPE (6.0; Carl Zeiss Meditec Inc), cleared by the FDA and now commercially available. This algorithm, which has been recently validated by comparison with manual segmentation, ${ }^{15,16}$ uses the RPE geometry and compares this segmentation map with a virtual map of the RPE free of deformations (RPE floor) (Figure 1). Using these two maps, the algorithm creates an elevation map that permits measurement of drusen area and volume. ${ }^{13}$ Elevations of $<20 \mu \mathrm{m}$ are not included. Areas of atrophy are detected by the algorithm as contiguous or geographic areas of hyperintensity. These areas of hyperintensity are evident in partial OCTprojection maps obtained by summing A-scans from a choroidal 'slab' below the RPE (loss of RPE in lesions resulted in increased choroidal reflectivity). Eyes with poor quality scans (signal strength $<7$ ) or features of neovascular AMD, such as subretinal fluid, intraretinal edema, subretinal tissue, or serous pigment epithelial detachments, in the OCT B-scans were excluded from subsequent quantitative lesion analysis. Because an important component of the planned analyses was to look for associations between the eyes, if one eye was ineligible (owing to missing scans, poor quality scans, or neovascular AMD) both the eyes of that subject were removed from subsequent analysis.

The Cirrus automated algorithm provided quantitative measurements of macular drusen area and volume within a central circle (CC) of $3 \mathrm{~mm}$ diameter and a surrounding perifoveal ring (PR) of 3-5 mm diameter, both of which were centered on the fovea. The RA measurements were provided for the entire $6 \times 6 \mathrm{~mm}^{2}$ by the software. 

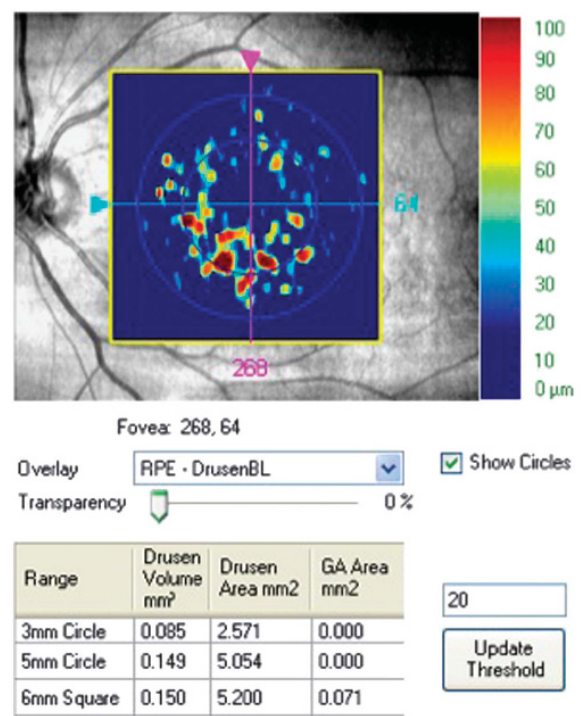
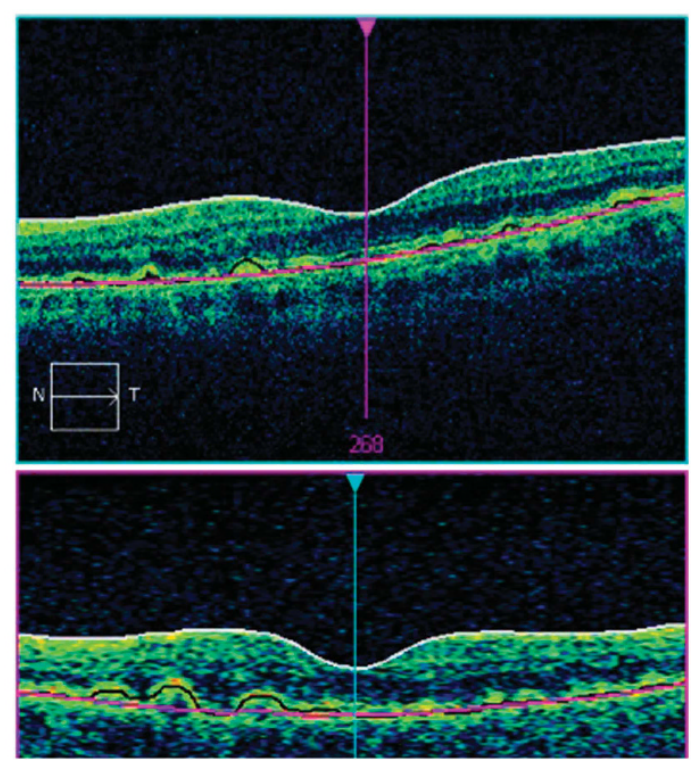

Figure 1 The Cirrus automated algorithm provides quantitative measurements of macular drusen area and volume within a $3 \mathrm{~mm}$ CC and a 3-5 mm surrounding PR. The RA measurements are provided for the entire $6 \times 6 \mathrm{~mm}^{2}$ area. It uses the RPE geometry (black line) and compares this segmentation map with a virtual map of the RPE free of deformations (pink line). Using these two maps, the algorithm creates an elevation map that permits measurement of drusen area and volume.

\section{Statistical methods}

The variables considered in this analysis included age (continuous and separated into four categories: 50-59, $60-69,70-79$, and $>80$ years of age), gender, past or present smoking history, years smoked (continuous and three categories: $<5,6-19$, and $>20$ years), SBP (continuous and separated into three categories: $<120$, $120-139$, and $>140 \mathrm{~mm} \mathrm{Hg}$ ), and the various quantitative measurements of macular drusen area, drusen volume, and RA for the right and left eyes. Comparison between the groups was done by analysis of variance.

Demographic comparisons between males and females used an independent samples $t$-test for mean age and $\chi^{2}$-square tests for frequencies by age groups and smoking status. Because these data included measures for both the eyes for all subjects, the analyses that tested the associations with OCT areas and volume used generalized estimating equations (GEE), which adjusted the correlation between the eyes. Paired $t$-tests were used to compare mean OCT measurements between the right and left eyes, and Spearman correlations were used to test the association of continuous age, years smoked (adjusted for age), and SBP with subject-averaged OCT measures. SAS V9.2 (SAS Inst., Cary NC, USA) software was used for all analyses; the accepted level of significance was $P<0.05$.

\section{Results}

A total of 268 subjects were recruited for this study, but 51 subjects were excluded owing to poor quality scans, missing scans, or features of neovascular AMD on OCT in at least one eye. Thus, 434 eyes of 217 consecutive subjects were included in this analysis. The sample included 122 women and 95 men with a mean age of $73 \pm 6.6$ years (range $50-89$ years). The majority of the population studied was between 70 and 79 years of age $(51.6 \%)$. There was no significant difference in age distribution $(P=0.61)$ between male and female groups. Twenty-three percent of the population had a history of smoking, with a much higher prevalence in the male population (51.6\% vs $0.8 \%, P<0.001)$. Age distribution and smoking status are shown in Table 1.

The drusen area and volume measurements were similar between males and females, but the RA found by OCT was significantly larger in women $(0.63 \pm 0.16$ vs $0.26 \pm 0.08 \mathrm{~mm}^{2}, P=0.05$ ). For both males and females, the average drusen area and volume were larger in the CC than in the PR (Table 2).

One-way analysis of variance determined that the drusen area, drusen volume, and RA differed among the various age groups $(P<0.001$, for all quantitative measurements). The perifoveal drusen area and volume, as well as the RA, were larger in older patients. The drusen area of the CC, in contrast, was relatively similar in patients of 70 years of age or more, with an area of $0.25 \pm 0.06 \mathrm{~mm}^{2}$ for the 70-79-year age group and $0.25 \pm 0.07 \mathrm{~mm}^{2}$ for the $>80$-year age group, and the CC drusen volume was smaller in the age $>80$-year age group $\left(0.009 \pm 0.003 \mathrm{~mm}^{3}\right)$ when compared with the subjects in the 70-79-year age group $\left(0.02 \pm 0.008 \mathrm{~mm}^{3}\right)$. 
In the older subjects (the $>80$-year age group), the perifoveal drusen area $\left(0.28 \pm 0.08 \mathrm{~mm}^{2}\right)$ and volume $\left(0.01 \pm 0.003 \mathrm{~mm}^{3}\right)$ were slightly larger than those of the CC $\left(0.25 \pm 0.07 \mathrm{~mm}^{2}\right.$ and $\left.0.009 \pm 0.003 \mathrm{~mm}^{3}\right)$.

PR and CC drusen area and volume and RA measurements were similar between the nonsmoking and smoking groups. In the smoking group, however, the

Table 1 Demographic characteristics of participants

\begin{tabular}{|c|c|c|c|c|}
\hline \multirow[b]{2}{*}{ Characteristics } & \multicolumn{4}{|c|}{ Number (\%) } \\
\hline & $\begin{array}{c}\text { Total } \\
217\end{array}$ & $\begin{array}{c}\text { Male } \\
95(43.8)\end{array}$ & $\begin{array}{c}\text { Female } \\
122(56.2)\end{array}$ & $\mathrm{P}$-value \\
\hline Age, years & & & & $0.61^{\mathrm{T}}$ \\
\hline Mean & 73 & 72.7 & 73.2 & \\
\hline Range & $50-89$ & $50-89$ & $51-89$ & \\
\hline Age group & & & & $0.57^{\mathrm{C}}$ \\
\hline $50-59$ & $5(2.3)$ & $2(2.1)$ & $3(2.5)$ & \\
\hline $60-69$ & $58(26.9)$ & $26(27.4)$ & $32(26.5)$ & \\
\hline $70-79$ & $120(51.6)$ & 49 (51.6) & $71(58.7)$ & \\
\hline$\geq 80$ & 33 (15.3) & $18(19.0)$ & $15(12.4)$ & \\
\hline Unknown & 1 & & 1 & \\
\hline Smoking status & & & & $<0.001^{\mathrm{C}}$ \\
\hline Unknown & $9(4.2)$ & $4(4.2)$ & $5(4.1)$ & \\
\hline Non-smoking & $158(72.8)$ & $42(44.2)$ & $116(95.1)$ & \\
\hline Smoker & $50(23.0)$ & 49 (51.6) & $1(0.8)$ & \\
\hline \multicolumn{5}{|l|}{ Years smoked } \\
\hline Mean & 22.1 & & & \\
\hline Range & $1-67$ & & & \\
\hline$\leq 5$ & 12 & & & \\
\hline$>6-19$ & 13 & & & \\
\hline$\geq 20$ & 22 & & & \\
\hline Unknown & 3 & & & \\
\hline
\end{tabular}

${ }^{\text {a }} \mathrm{T}$, independent samples $t$-test; $\mathrm{C}, \chi^{2}$ test. perifoveal drusen area $(P=0.05)$ and volume $(P=0.005)$ had an increasing correlation with the number of years smoked (Table 3) when adjusted for age. No significant difference was noted between the groups with different smoking duration.

The OCT findings were associated with SBP (Table 3). Larger drusen area and volume in the PR, as well as RA, were correlated with increase in SBP. The drusen area in the CC differed significantly among the SBP groups $(P=0.05)$. Measurements were $0.07 \pm 0.02 \mathrm{~mm}^{2}$ for the $<120 \mathrm{~mm} \mathrm{Hg}$ group, $0.225 \pm 0.07 \mathrm{~mm}^{2}$ for the 120 $139 \mathrm{~mm} \mathrm{Hg}$ group, and $0.396 \pm 0.19 \mathrm{~mm}^{2}$ for the $>140 \mathrm{~mm} \mathrm{Hg}$ group.

A significant correlation $(P<0.001)$ was found between the right and left eyes with respect to drusen area, drusen volume, and RA, as determined by OCT. $\mathrm{CC}$ drusen area and volume showed a stronger correlation between eyes compared with the PR (for area $r=0.72$ vs 0.54 and volume $r=0.66$ vs $0.58, P<0.001$ for all correlations). The correlation coefficient for RA between eyes was 0.48 .

Table 4 demonstrates the relationship between drusen measurements in the CC and PR, as well as their relationship with RA in the same eye. The volume measured appeared to show a similar correlation compared with area ( $r=0.75$ vs 0.71$)$. The larger RA was also correlated with larger drusen area in the PR.

\section{Discussion}

Segmentation of the retinal layers and measurement of drusen area, drusen volume, and RA would appear to be critical for quantitative AMD studies. Automated algorithms to segment the OCT images accurately and

Table 2 Association of age and gender with OCT areas and volumes

\begin{tabular}{|c|c|c|c|c|c|}
\hline & Area CC & Area $P R$ & Volume CC & Volume PR & $R A$ \\
\hline \multicolumn{6}{|l|}{ Sex, mean $\pm S D$} \\
\hline Male $(n=95)$ & $0.1695 \pm 0.0549$ & $0.1153 \pm 0.0372$ & $0.0123 \pm 0.0057$ & $0.0051 \pm 0.0020$ & $0.2600 \pm 0.0878$ \\
\hline Female $(n=122)$ & $0.2414 \pm 0.0629$ & $0.1988 \pm 0.0507$ & $0.0165 \pm 0.0070$ & $0.0095 \pm 0.0032$ & $0.6307 \pm 0.1641$ \\
\hline$P$-value ${ }^{\mathrm{a}}$ & 0.39 & 0.18 & 0.64 & 0.25 & 0.05 \\
\hline \multicolumn{6}{|l|}{ Age group (years) } \\
\hline $50-59(n=5)$ & $0.0100 \pm 0.0089$ & $0.0000 \pm 0.0000$ & $0.0002 \pm 0.0002$ & $0.0001 \pm 0.0001$ & $0.0200 \pm 0.0179$ \\
\hline $60-69(n=58)$ & $0.1233 \pm 0.0507$ & $0.0862 \pm 0.0362$ & $0.0077 \pm 0.0041$ & $0.0034 \pm 0.0016$ & $0.1793 \pm 0.0904$ \\
\hline $70-79(n=120)$ & $0.2504 \pm 0.0698$ & $0.1746 \pm 0.0509$ & $0.0202 \pm 0.0081$ & $0.0090 \pm 0.0034$ & $0.3867 \pm 0.1152$ \\
\hline$\geq 80(n=33)$ & $0.2515 \pm 0.0783$ & $0.2803 \pm 0.0883$ & $0.0094 \pm 0.0031$ & $0.0108 \pm 0.0036$ & $1.3561 \pm 0.4556$ \\
\hline$P$-value ${ }^{\text {a }}$ & $<0.001$ & $<0.001$ & $<0.001$ & $<0.001$ & $<0.001$ \\
\hline $\begin{array}{l}\text { Spearman correlation } \\
\text { with continuous age }\end{array}$ & $0.21, P=0.002$ & $0.25, P<0.001$ & $0.25, P<0.001$ & $0.26, P<0.001$ & $0.25, P<0.001$ \\
\hline
\end{tabular}

Abbreviations: CC, central circle; PR, perifoveal ring; RA, retinal pigment epithelium atrophy.

${ }^{a}$ Generalized estimating equations (GEE). 
Table 3 Association of smoking and SBP with OCT areas and volumes

\begin{tabular}{|c|c|c|c|c|c|}
\hline & Area CC & Area $P R$ & Volume CC & Volume PR & $R A$ \\
\hline \multicolumn{6}{|l|}{ Smoking status, mean $\pm S D$} \\
\hline Nonsmokers $(n=158)$ & $0.2117 \pm 0.0517$ & $0.1582 \pm 0.0397$ & $0.0152 \pm 0.0056$ & $0.0075 \pm 0.0025$ & $0.5234 \pm 0.1301$ \\
\hline Smokers $(n=50)$ & $0.1950 \pm 0.0862$ & $0.1460 \pm 0.0614$ & $0.0139 \pm 0.0094$ & $0.0069 \pm 0.0035$ & $0.3000 \pm 0.1372$ \\
\hline$P$-value ${ }^{\text {a }}$ & 0.87 & 0.87 & 0.91 & 0.89 & 0.24 \\
\hline \multicolumn{6}{|l|}{ Years smoked } \\
\hline$\leq 5(n=12)$ & $0.0667 \pm 0.0596$ & $0.0042 \pm 0.0040$ & $0.0041 \pm 0.0038$ & $0.0000 \pm 0.0000$ & $0.0125 \pm 0.0120$ \\
\hline $6-19(n=13)$ & $0.4269 \pm 0.3052$ & $0.1885 \pm 0.1488$ & $0.0403 \pm 0.0347$ & $0.0123 \pm 0.0110$ & $0.1077 \pm 0.0995$ \\
\hline$\geq 20(n=22)$ & $0.1545 \pm 0.0515$ & $0.2159 \pm 0.1041$ & $0.0055 \pm 0.0019$ & $0.0083 \pm 0.0042$ & $0.4705 \pm 0.2699$ \\
\hline$P$-value ${ }^{\mathrm{a}}$ & 0.32 & 0.06 & 0.59 & 0.08 & 0.15 \\
\hline \multicolumn{6}{|l|}{ SBP, $m m \mathrm{Hg}$} \\
\hline$<120(n=68)$ & $0.0772 \pm 0.0258$ & $0.0985 \pm 0.0396$ & $0.0029 \pm 0.0010$ & $0.0040 \pm 0.0017$ & $0.3059 \pm 0.1389$ \\
\hline $120-139(n=66)$ & $0.2250 \pm 0.0738$ & $0.1568 \pm 0.0626$ & $0.0136 \pm 0.0063$ & $0.0082 \pm 0.0047$ & $0.3614 \pm 0.1569$ \\
\hline$\geq 140(n=31)$ & $0.3968 \pm 0.1913$ & $0.2839 \pm 0.1195$ & $0.0370 \pm 0.0244$ & $0.0128 \pm 0.0067$ & $0.9565 \pm 0.3784$ \\
\hline$P$-value ${ }^{a}$ & 0.05 & 0.29 & 0.09 & 0.34 & 0.27 \\
\hline $\begin{array}{l}\text { Spearman correlation with } \\
\text { continuous years smoked, adjusted for age }\end{array}$ & $0.23, P=0.12$ & $0.29, P=0.05$ & $0.20, P=0.17$ & $0.40, P=0.005$ & $0.24, P=0.10$ \\
\hline Spearman correlation with continuous SBP & $0.06, P=0.42$ & $0.18, P=0.01$ & $0.08, P=0.26$ & $0.18, P=0.02$ & $0.15, P=0.05$ \\
\hline
\end{tabular}

Abbreviations: CC, central circle; OCT, optical coherence tomography; PR, perifoveal ring; RA, retinal pigment epithelium atrophy; SBP, systolic blood pressure.

${ }^{\mathrm{a}}$ Generalized estimating equations (GEE).

Table 4 Correlations between RPE atrophy area and drusen area and volume in the CC and PR

\begin{tabular}{lccc}
\hline Variable 1 & Variable 2 & $\begin{array}{c}\text { Spearman correlation } \\
\text { coefficient }\end{array}$ & P-value \\
\hline Area CC & Area PR & 0.71 & $<0.001$ \\
Volume CC & Volume PR & 0.75 & $<0.001$ \\
Area CC & RA & 0.48 & $<0.001$ \\
Area PR & RA & 0.67 & $<0.001$ \\
Volume CC & RA & 0.52 & $<0.001$ \\
Volume PR & RA & 0.63 & $<0.001$ \\
\hline
\end{tabular}

Abbreviations: CC, central area; PR, perifoveal ring; RA, retinal pigment epithelium atrophy.

reproducibly have been described, ${ }^{13-16}$ and, importantly, have now become available in commercial devices. In the present study, we demonstrate that these algorithms may be used to study and describe drusen and RA burden in a population-based study of elderly patients.

Our analysis confirms that, in general, larger and more abundant drusen are found with increasing age, but in the $\mathrm{CC}$, after the age of 70 years, the drusen volume and area appear to stabilize and are eventually smaller after the age of 80 years. Although this correlation between age and drusen area/volume is statistically significant, the strength of the association is relatively weak $(r=0.21-0.25)$, suggesting that many other factors (eg, genetic and environment) may contribute to the variability in drusen burden. RA, in contrast, is progressively larger with advanced age when analyzed using this segmentation algorithm. Although the RA algorithm measures the entire $6 \times 6 \mathrm{~mm}^{2}$ and not the CC alone, one suspects that the increase in the RA in the central area may account for some of the apparent decrease in the CC drusen measurements in the $>80$-year age group. These findings may be consistent with the regression of soft macular drusen and evolution of atrophy that has been described in clinical and hitopathological studies. ${ }^{18}$ Gass $^{19}$ first noted that drusen could fade and disappear, leaving only an irregular mottling of the RPE. He also observed that most cases of GA followed the fading of drusen, resulting in degeneration and atrophy of the RPE and photoreceptors. Our observations agree with the clinical impression that GA is rare before the age of 55 years and that it becomes more common in individuals aged 75 years or older.

Drusen area and volume were similar in males and females, but interestingly, RA was significantly more common in women. According to one study, the diagnosis of late AMD has been reported to be slightly more frequent in women than in men. In this study a higher prevalence of neovascular AMD and no significant difference in GA was observed. ${ }^{20}$ Other studies show a similar prevalence of any AMD stage in males and females. ${ }^{21}$ 
Cigarette smoking has been found to be related to late age-related maculopathy in some, ${ }^{22-25}$ but not all, ${ }^{26-29}$ epidemiologic studies. A smoking history was neither associated with larger drusen area and volume, nor with RA in our population. In part, the small number of cases, particularly of women smokers, may explain this. We did not make any distinction between current past smoking history, and possibly some of our subjects were former smokers. It has been reported that, although previous smoking history also increases the progression of AMD, current smoking is more likely to increase the incidence of AMD lesions. ${ }^{29}$ McCarty et $a l^{30}$ argued that the total duration of smoking history was the most significant factor for development of AMD rather than pack years, current, or former smoking status. In other studies, ${ }^{31}$ the pack years of cigarette smoking has proven to be a better correlate than the number of years of smoking, and it was the most significant risk factor for AMD. A doseresponse effect has been demonstrated: the risk of developing AMD increases as the intensity of smoking increases. $^{32}$ In our Amish population, an increased duration of smoking did appear to be associated with a larger drusen area and volume in the PR.

In the present study, an increase in SBP was directly correlated with larger drusen area and volume in the perifoveal zone and with larger RA. The relationship between blood pressure and AMD has proven to be inconsistent in epidemiologic population-based studies, with some studies suggesting an increased risk of developing AMD with increased pulse pressure. ${ }^{21}$ In the Beaver Dam study, SBP, hypertension, and pulse pressure were significantly associated with RPE depigmentation, progression of AMD, and incidence of neovascular AMD, but not GA. ${ }^{33}$ The mechanism by which hypertension can increase the risk of AMD is not immediately apparent. However, age-related degenerative changes in collagen and elastin are known to produce a decrease in the distensibility of blood vessels. ${ }^{34}$ This in turn results in higher SBP and lower diastolic blood pressure and widening of the pulse pressure. Klein $e a^{33}$ postulated that a wide pulse pressure may be a marker of similar degenerative changes also occurring in the Bruch membrane of these individuals' eyes, thus increasing the risk of development and progression of AMD. Although we found a significant correlation, our conclusions are limited as the blood pressure reading was acquired just once and may not reflect a chronic systemic hypertension diagnosis.

The right and left eyes of subjects demonstrate a high correlation in drusen and RA measurements using the automated OCT algorithms. This finding is in agreement with a previous analysis that demonstrated good to excellent symmetry for all ophthalmoscopic and fluorescein angiographic characteristics of drusen in the central and peripheral areas of the posterior pole between both the eyes of subjects with AMD. ${ }^{35}$ Sunness et $a l^{36}$ described a high correlation in the size and progression of GA between both eyes. Studies suggest that $48-65 \%$ of prevalent GA cases show bilateral involvement. ${ }^{37}$ Thus, our automated OCT observations of RA are consistent with previous observations of bilateral incidence $^{38}$ and with ophthalmoscopic assessment of AMD symmetry. ${ }^{19,39}$

Despite these apparent observations and associations, our study is not without limitations. First, although this was a population study, we only studied individuals aged 50 years or older. Thus, information about OCTquantified drusen burden in younger individuals is unknown. Our study does demonstrate that OCT-based assessment can be applied to population analyses. Furthermore, our OCT data may be correlated with future genetic information that may be forthcoming from this population. Second, our analysis only used the automated quantitative data provided by the instrument. We did not perform additional qualitative analysis of drusen morphology or other OCT features of AMD, such as the presence of intraretinal hyperreflective foci (known to correlate with areas of RPE migration), nor did we correct subtle segmentation errors. On the other hand, by using commercial algorithms that had been FDA-cleared and previously validated for reliability and accuracy, the data considered in our analysis can easily be compared with the data obtained in future studies in other and larger populations. Third, the commercial drusen segmentation algorithm only includes RPE elevations that exceed a threshold of $20 \mu \mathrm{m}$. Although very shallow drusen are likely to be ignored by this analysis, they would probably only contribute a small amount to the total area or volume in eyes with significant numbers of larger drusen even if they were to be included. Fourth, color fundus photographs were not classified or compared with the drusen and RA segmented by the software. Color fundus photographs offer potentially complementary information to SD-OCT and both may have an important role in assessing drusen and GA in patients with non-exudative AMD. ${ }^{11}$ While this would have been an interesting analysis, this has been evaluated in other studies. ${ }^{40}$ Finally, the commercial RA segmentation algorithm was designed to include all contiguous areas that demonstrated significant transmission of light into the choroid with associated increased choroidal reflectivity. Although these measurements have been shown to compare favorably with fundus autofluorescence-based measures of RA, ${ }^{41}$ areas of severe depigmentation of the RPE without actual loss of the RPE may produce a similar appearance on OCT and thus may be inadvertently included in the OCT-derived RA measurements. 
Polarization-sensitive SD-OCT combines the advantage of SD-OCT imaging with a selective identification of the polarization state of backscattered light. Because the melanosomes of the RPE change the polarization state in a random manner,

PS-OCT is capable of precisely depicting its exact location and configuration. This selectivity can be used for a reliable automated segmentation of alterations at the retina-RPE boundary. ${ }^{42}$ Further studies are needed to evaluate the differences between the two methods.

Despite these limitations, the OCT-derived automated analyses in the Amish population suggest that increasing age appears to be an important risk factor for increased OCT drusen area and volume in the CC and PR although this increase in drusen area in the CC does not continue after the age of 70 years. Drusen and RA measurements are highly correlated and similar between the eyes of the same individual. The number of continuous years smoked and SBP are also associated with an increased area and volume of perifoveal drusen. Female gender, age, and SBP are all associated with RA to a greater extent. These findings may be useful as a starting point in guiding future, larger, populationbased studies on the prevalence of features of nonneovascular AMD, and in better phenotyping and characterization of populations for genetic association studies.

\section{Summary}

What was known before

- Color fundus photography was the only imaging modality used to evaluate the severity and progression of AMD in major epidemiologic eye disease studies.

- This imaging technique has limitations with regard to the measurement of RPE atrophy and to the precise quantification of drusen boundaries.

- OCT provides the opportunity to assess the effect of drusen and RA on the geometry of the RPE in vivo.

What this study adds

- Automated OCT-based assessment of lesions associated with non-neovascular AMD can be applied to population analyses and may allow for more complete and quantitative assessment of patients for longitudinal assessments.

\section{Conflict of interest}

Dr Sadda has previously shared in royalties from intellectual property licensed by the Doheny Eye Institute to Topcon Medical Systems. He has served in the past as a consultant to Heidelberg Engineering and receives research support from Optos, Carl Zeiss Meditec, and Optovue. The remaining authors declare no conflict of interest.

\section{Acknowledgements}

We thank Laurie Dustin for statistical analysis and Susan Clarke for text review. This work was supported in part by NEI core grant EY03040, the Beckman Institute for Macular Research, a Research to Prevent Blindness Physician Scientist Award, the CAPES Foundation (Brasilia, Brazil), Research to Prevent Blindness Foundation, Pennsylvania Department of Health, FM Kirby Family Trust, and Mackall Trust.

\section{References}

1 Bressler NM. Age-related macular degeneration is the leading cause of blindness. JAMA 2004; 291: 1900-1901.

2 Wang JJ, Foran S, Smith W, Mitchell P. Risk of age-related macular degeneration in eyes with macular drusen or hyperpigmentation: the Blue Mountains Eye Study cohort. Arch Ophthalmol 2003; 121: 658-663.

3 Butt AL, Lee ET, Klein R, Russell D, Ogola G, Warn A et al. Prevalence and risks factors of age-related macular degeneration in Oklahoma Indians: the Vision Keepers Study. Ophthalmology 2011; 118: 1380-1385.

4 Abdelsalam A, Del Priore L, Zarbin MA. Drusen in age-related macular degeneration: pathogenesis, natural course, and laser photocoagulation-induced regression. Surv Ophthalmol 1999; 44: 1-29.

5 Fleckenstein M, Adrion C, Schmitz-Valckenberg S, Göbel AP, Bindewald-Wittich A, Scholl $\mathrm{H}$ et al. Concordance of disease progression in bilateral geographic atrophy due to AMD. Invest Ophthalmol Vis Sci 2010; 5: 637-642.

6 Sunness JS. The natural history of geographic atrophy, the advanced atrophic form of age-related macular degeneration. Mol Vis 1999; 5: 25.

7 Strahlman ER, Fine SL, Hillis A. The second eye of patients with senile macular degeneration. Arch Ophthalmol 1983; 101: 1191-1193.

8 Roy M, Kaiser-Kupfer M. Second eye involvement in age-related macular degeneration: a four-year prospective study. Eye 1990; 4: 813-818.

9 Wang JJ, Mitchell P, Smith W, Cumming RG. Bilateral involvement by age related maculopathy lesions in a population. Br J Ophthalmol 1998; 82: 743-747.

10 Coffey AJ, Brownstein S. The prevalence of macular drusen in postmortem eyes. Am J Ophthalmol 1986; 102: 164-171.

11 Yehoshua Z, Rosenfeld PJ, Gregori G, Penha F. Spectral domain optical coherence tomography imaging of dry age-related macular degeneration. Ophthalmic Surg Lasers Imaging 2010; 41(Suppl): S6-14.

12 Fleckenstein M, Schmitz-Valckenberg S, Adrion C, Visvalingam S, Göbel AP, Mössner A et al. Progression of age-related geographic atrophy: role of the fellow eye. Invest Ophthalmol Vis Sci 2011; 52: 6552-6557.

13 Gregori G, Wang F, Rosenfeld PJ, Yehoshua Z, Gregori NZ, Lujan BJ et al. Spectral domain optical coherence tomography imaging of drusen in nonexudative age-related macular degeneration. Ophthalmology 2011; 118: 1373-1379.

14 Chiu SJ, Izatt JA, O'Connell RV, Winter KP, Toth CA, Farsiu S. Validated automatic segmentation of AMD pathology including drusen and geographic atrophy in SD-OCT images. Invest Ophthalmol Vis Sci 2012; 53: 53-61. 
15 Nittala M, Ruiz-Garcia H, Sadda SR. Accuracy and reproducibility of automated drusen segmentation in eyes with non-neovascular age- related macular degeneration. Invest Ophthalmol Vis Sci 2012; 53: 8319-8324.

16 Yehoshua Z, Garcia Filho CA, Penha FM, Gregori G, Stetson PF, Feuer WJ et al. Comparison of geographic atrophy measurements from the OCT fundus image and the sub-RPE slab image. Ophthalmic Surg Lasers Imaging Retina 2013; 44: 127-32.

17 Yehoshua Z, Wang F, Rosenfeld P, Penha FM, Feuer WJ, Gregori G. Natural history of drusen morphology in agerelated macular degeneration using spectral domain optical coherence tomography. Ophthalmology 2011; 118: 2434-2441.

18 Sallo FB, Rechtman E, Peto T, Stanescu-Segall D, Vogt G, Bird AC et al. Functional aspects of drusen regression in age-related macular degeneration. Br J Ophthalmol 2009; 93 : $1345-1350$

19 Gass JD. Drusen and disciform macular detachment and degeneration. Arch Ophthalmol 1973; 90: 206-217.

20 Rudnicka AR, Jarrar Z, Wormald R, Penha FM, Feuer WJ, Gregori G. Age and gender variations in age-related macular degeneration prevalence in populations of European ancestry: a meta-analysis. Ophthalmology 2012; 119(3): 571-580.

21 Klein R, Klein BEK, Knudtson MD, Wong TY, Cotch MF, Liu $\mathrm{K}$ et al. Prevalence of age-related macular degeneration in 4 racial/ethnic groups in the multi-ethnic study of atherosclerosis. Ophthalmology 2006; 113: 373-380.

22 The Eye Disease Case-Control Study Group. Risk factors for neovascular age-related macular degeneration. Arch Ophthalmol 1992; 110: 1701-1708.

23 Klein R, Klein BEK, Linton KLP, DeMets DL. The Beaver Dam Eye Study: the relation of age-related maculopathy to smoking. Am J Epidemiol 1993; 137: 190-200.

24 Seddon JM, Willett WC, Speizer FE, Hankinson SE. A prospective study of cigarette smoking and age-related macular degeneration in women. JAMA 1996; 276: 1141-1146.

25 Christen WG, Glynn RJ, Manson JE, Ajani UA, Buring JE. A prospective study of cigarette smoking and risk of age-related macular degeneration in men. JAMA 1996; 276: 1147-1151

26 Maltzman BA, Mulvihill MN, Greenbaum A. Senile macular degeneration and risk factors: a case-control study. Ann Ophthalmol 1979; 11: 1197-1201.

27 Blumenkranz MS, Russell SR, Robey MG, KottBlumenkranz R, Penneys N. Risk factors in age-related maculopathy complicated by choroidal neovascularization. Ophthalmology 1986; 93: 552-558.

28 West SK, Rosenthal FS, Bressler NM, Bressler SB, Munoz B, Fine SL et al. Exposure to sunlight and other risk factors for age-related macular degeneration. Arch Ophthalmol 1989; 107: 875-879.

29 Klein R, Klein BE, Moss SE. Relation of smoking to the incidence of age-related maculopathy. The Beaver Dam Eye Study. Am J Epidemiol 1998; 147: 103-110.
30 McCarty CA, Mukesh BN, Fu CL, Mitchell P, Wang JJ, Taylor HR. Risk factors for age-related maculopathy: the Visual Impairment Project. Arch Ophthalmol 2001; 119: 1455-1462.

31 Khan JC, Thurlby DA, Shahid H, Clayton DG, Yates JR, Bradley $\mathrm{M}$ et al. Smoking and age related macular degeneration: the number of pack years of cigarette smoking is a major determinant of risk for both geographic atrophy and choroidal neovascularisation. $\mathrm{Br} J$ Ophthalmol 2006; 90: 75-80.

32 Thornton J, Edwards R, Mitchell P, Harrison RA, Buchan I, Kelly SP. Smoking and age-related macular degeneration: a review of association. Eye 2005; 19: 935-944.

33 Klein R, Klein BE, Tomany SC, Cruickshanks KJ. The association of cardiovascular disease with the long-term incidence of age-related maculopathy: the Beaver Dam Eye Study. Ophthalmology 2003; 110: 636-643.

34 Choudhury F, Varma R, McKean-Cowdin R, Klein R, Azen SP. Los Angeles Latino Eye Study Group. Risk factors for four-year incidence and progression of age-related macular degeneration: the Los Angeles Latino Eye Study. Am J Ophthalmol 2011; 152: 385-395.

35 Leibowitz HM, Krueger DE, Maunder LR, Milton RC, Kini MM, Kahn HA et al. The Framingham Eye Study monograph; an ophthalmological and epidemiological study of cataract, glaucoma, diabetic retinopathy, macular degeneration. Surv Ophthalmol 1980; 24: 335-610.

36 Sunness JS, Gonzalez-Baron J, Applegate CA, Bressler NM, Tian Y, Hawkins B et al. Enlargement of atrophy and visual acuity loss in the geographic atrophy form of age-related macular degeneration. Ophthalmology 1999; 106: $1768-1779$.

37 Bellmann C, Jorzik J, Spital G, Unnebrink K, Pauleikhoff D, Holz FG. Symmetry of bilateral lesions in geographic atrophy in patients with age-related macular degeneration. Arch Ophthalmol 2002; 120: 579-584.

38 Coffey AJH, Brownstein S. The prevalence of macular drusen in postmortem eyes. Am J Ophthalmol 1986; 102: 164-171.

39 Barondes M, Pauleikhoff D, Chisholm IC, Minassian D, Bird AC. Bilaterality of drusen. Br J Ophthalmol 1990; 74: 180-182.

40 Jain N, Farsiu S, Khanifar A, Bearelly S, Smith RT, Izatt JA et al. Quantitative comparison of drusen segmented on SD OCT versus drusen delineated on color fundus photographs. Invest Ophthalmol Vis Sci 2012; 51: 4875-4883.

41 Yehoshua Z, Rosenfeld PJ, Gregori G, Feuer WJ, Falcão M, Lujan BJ et al. Progression of geographic atrophy in age-related macular degeneration imaged with spectral domain optical coherence tomography. Ophthalmology 2011; 118: 679-686.

42 Schlanitz FG, Baumann B, Spalek T, Schütze C, Ahlers C, Pircher $\mathrm{M}$ et al. Performance of automated drusen detection by polarization-sensitive optical coherence tomography. Invest Ophthalmol Vis Sci 2011; 52: 4571-4579. 